\title{
The decision making and techniques in lung cancer patients with aortic resection and reconstruction: surgery for lung cancer with aortic wall invasion
}

\author{
Tugba Cosgun ${ }^{1}$, Erkan Kaba ${ }^{1}$, Kemal Ayalp ${ }^{2}$, Alper Toker ${ }^{2}$ \\ ${ }^{1}$ Thoracic Surgery Department, Istanbul Bilim University, Istanbul, Turkey; ${ }^{2}$ Thoracic Surgery Department, Istanbul Florence Nightingale, Istanbul, \\ Turkey \\ Contributions: (I) Conception and design: A Toker; (II) Administrative support: A Toker, E Kaba; (III) Provision of study materials or patients: A \\ Toker, T Cosgun; (IV) Collection and assembly of data: A Toker, K Ayalp; (V) Data analysis and interpretation: A Toker; (VI) Manuscript writing: All \\ authors; (VII) Final approval of manuscript: All authors. \\ Correspondence to: Tugba Cosgun. Istanbul Bilim University, Sisli Merkez Mah. Abidei Hurriyet Cad. No:164 34387 Sisli/Istanbul, Turkey. \\ Email: tugba_cosgun@hotmail.com.
}

\begin{abstract}
The number of operations performed worldwide for T4 is still limited although the complete anatomical resection is the best treatment option for non-small cell lung cancer (NSCLC). Aortic invasion and its surgical treatment is accepted as one of the extreme situations. Surgical management with low morbidity and mortality, complete en bloc resection with microscopically clear margins with no nodal disease, and inclusion of multimodality treatment may increase survival.
\end{abstract}

Keywords: Aortic invasion; aortic resection; non-small cell lung cancer (NSCLC); cardiopulmonary bypass (CPB)

Received: 05 October 2018; Accepted: 26 October 2018; Published: 21 November 2018.

doi: $10.21037 /$ shc.2018.11.01

View this article at: http://dx.doi.org/10.21037/shc.2018.11.01

\section{Introduction}

Resection of aorta for lung cancer invasion is an extreme situation, and the number of operations performed worldwide for T4 disease is limited. Recently, the Surveillance, Epidemiology, and End Results (SEER) database demonstrated that the resection rate of T4 tumors was $9 \%$, with an overall 30 -day mortality of $10 \%$ (1). The database also showed that the 5 -year survival rate after the resection of $\mathrm{T} 4$ tumors has improved from $15 \%$ to $35 \%$ in the past 20 years (1). Developments in North America were parallel with those of obtained in Japan. A study conducted in Japan comprising 215 patients with T4 lung cancer who were operated on in 2004 reported that the 5 -year overall survival rate was $35 \%$ and that it may increase to $50 \%$ in younger patients without lymph node metastasis (2). A similar outcome was observed in Europe, especially in patients with $\mathrm{R} 0$ resection and without mediastinal lymph node metastasis $(3,4)$. All these outcomes were the results of surgically proficient thoracic surgery departments, and the surgeries should be recognized as exceptional conditions.

Primary lung tumors with a potential for invasion to the aorta may be found in a heterogeneous patient population. The candidates may comprise T2, T3, and T4 tumors. Only visceral pleural involvement may mimic aortic invasion under T2 circumstances. In T3 tumors, the parietal pleura over the mediastinal aorta may be involved, whereas in $\mathrm{T} 4$ tumors, the aorta may be invaded directly. Recurrent laryngeal nerve invasion is a characteristic finding of invasion at the level of the aortic arch. This type of radiological presentation indicates that the cancer may be anywhere between stages IB and IIIB.

Prognosis may be favorable with high-quality surgical management, complete en bloc resection with microscopically clear margins with no nodal disease, and inclusion of multimodality treatment. Therefore, it is the surgeon's priority to accurately select the suitable candidates, perform a proper preoperative mediastinal nodal staging, and avoid an unnecessary risky operation. 

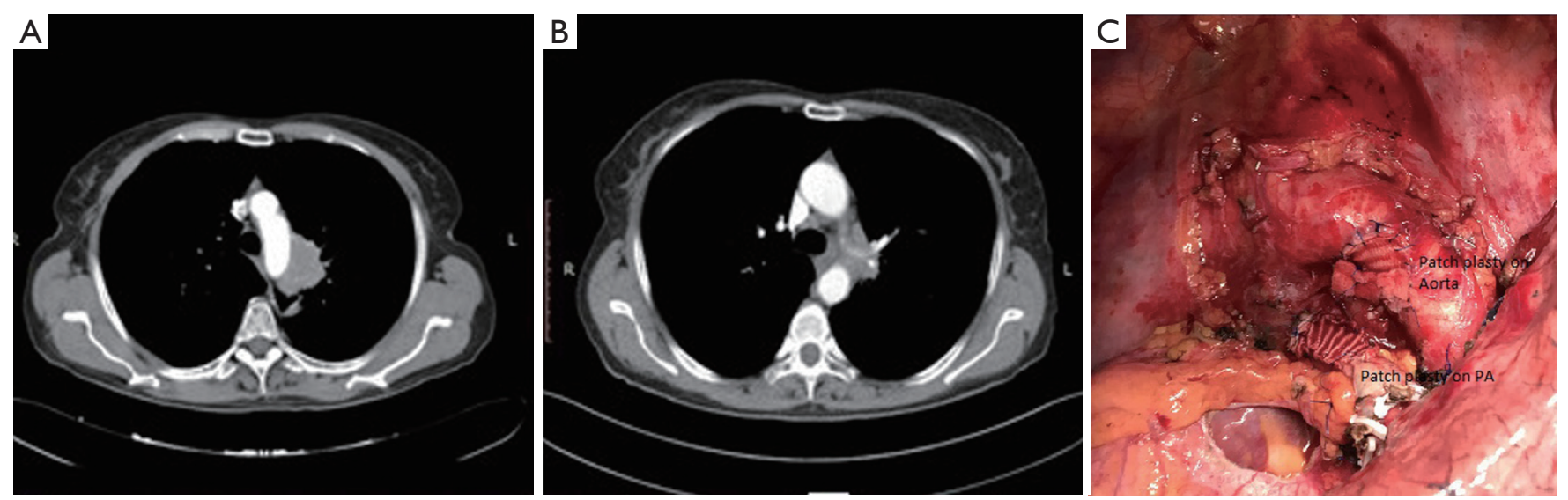

Figure $1(A, B)$ Chest tomography of a patient with aortic wall and ipsilateral pulmonary arterial involvement. (A) Tumor invading aorta; (B) the tumor invading pulmonary artery. The patient underwent an induction treatment. Mediastinoscopy revealed no N2 disease. (C) Patch plasty on aorta and pulmonary artery (PA) are shown.

\section{Radiological investigations}

\section{Computed tomography (CT) and magnetic resonance imaging (MRI)}

Contrast enhanced CT of the chest may demonstrate the risk for aortic invasion. It can also help determine the type of an additional lung surgery that might be required, such as a bronchial or a pulmonary arterial sleeve (5).

CT combined with angiography and venography may precisely delineate the vessels, especially when there is a suspicion of pulmonary artery $(\mathrm{PA})$ invasion in addition to the aorta (Figure 1) (6).

Many times, the assessment of tumor invasion to adjacent structures are limited. While concentrating on an aortic invasion, a surgeon can easily miss the invasion to the esophageal wall, ipsilateral PA (Figure 1), the primary PA (Figures 1,2), vertebra (Figure 3), and the primary bronchus. The invasion of $\mathrm{PA}$ and the bronchus may require treatment options such as either a bronchial or a pulmonary arterial sleeve or a PA resection and patch plasty in addition to an aortic resection.

Nevertheless, there are at least three criteria for diagnosing a vascular invasion using CT. These include the disappearance of the fat plane between the tumor and the vessel, the angle of tumor invasion that is $>90^{\circ}$, and the distortion and stenosis of the vessel lumen (7). According to the literature, the sensitivity, specificity, and accuracy of CT in confirming invasion into the mediastinum are $40-84 \%, 57-94 \%$, and 56-89\%, respectively (8). Gdeedo suggested that mediastinal structure involvement (T4) could not be reliably detected by a CT scan in about $50 \%$ of the patients (9). Spaggiari recommended considering the invasion of the diameter of the aorta on the CT scan. If the invasion involves $>50 \%$ of the diameter, which implies $>180^{\circ}$, then it could be considered to be infiltrated by the tumor; if the invasion is $<50 \%$, then the tumor is considered to be attached but may not be considered as involving the aorta (10).

Cine MRI is known to be a better method for determining aortic wall invasion. It provides the best result using a gap between cardiac motion and respiratory movements. When a CT scan or a conventional MRI displays equivocal results and is unable to identify the aortic invasion by cancer, respiratory dynamic (RD) MRI can be used to obtain additional information, especially for tumors close to the descending thoracic aorta (11).

\section{Factors affecting the outcome}

T4 disease may exhibit different outcomes and high heterogeneity despite the use of trimodality therapy; for example, the 5 -year overall survival rate in patients with Pancoast tumor was $86 \%$, whereas it decreased to $60 \%$ in patients with centrally located tumors without a pathological N2-positive disease (12). Another factor affecting the outcome may be the use of cardiopulmonary bypass (CPB), which has been claimed to have immunosuppressive effects and poor prognosis. It has been reported that $\mathrm{CPB}$ is used selectively during the complete resection of $\mathrm{T} 4$ tumors (13-16). The use of CPB was primarily related to 

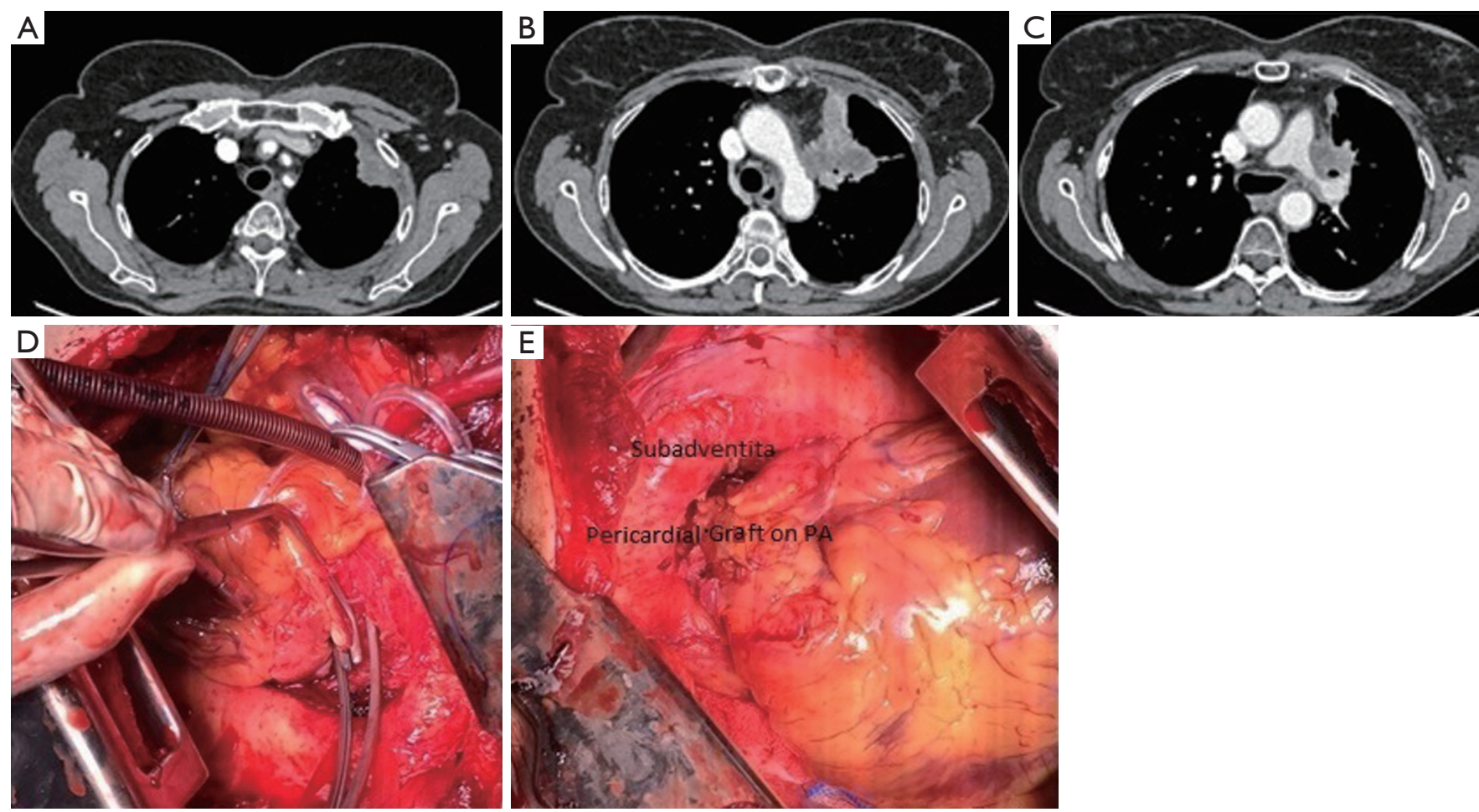

Figure 2 Large tumor with (A) chest wall, (B) subadventitial aorta, (C) pulmonary artery (PA) invasion. She underwent induction chemotherapy. Mediastinoscopy showed no N2 involvement. (D) Pericardial patch plasty to main PA under CPB. (E) Aortic involvement was resected subadventitially.
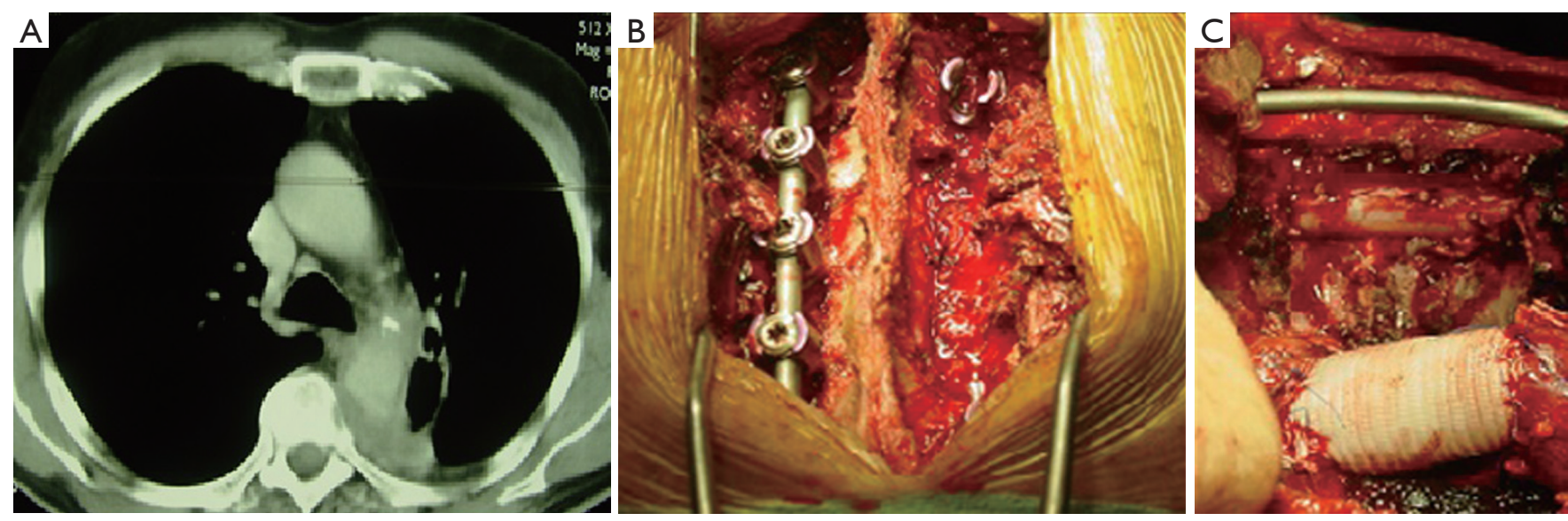

Figure 3 (A) Image of chest computer tomography of patient with aortic and vertebral involvement; (B) surgical treatment after invasion of vertebral canal with Spinal surgery; (C) after tube graft interposition for aorta invasion.

aortic $(43 \%)$ and left atrium or pulmonary vein resections (24\%) (14).

Small case series demonstrating the feasibility of CPB use have reported favorable short- and long-term outcomes for NSCLC $(13,15)$. However, a national registry did not provide similar outcomes and observed unacceptable high mortality ( $>25 \%)$ and morbidity $(>70 \%)$ rates $(16)$. The majority of studies have emphasized that an unplanned use of CPB due to a major vessel injury was almost always associated with poor results and outcomes, which are not 
comparable to those obtained with planned use of CBP $(13,16)$. The planned use of CPB for highly selective patients in centers with high experience may result in similar oncologic outcomes that may be similar to those obtained without CPB use (17).

The primary aims of this review were to analyze (I) the evidence supporting the resection of aorta in patients with NSCLC, (II) the use of neoadjuvant therapy for NSCLC tumors that invade the aorta, and (III) the outcomes following surgical resection in these patients.

\section{Aortic involvement}

NSCLC tumors invading the aorta have been successfully resected due to the increasing developments in the use of preoperative endovascular stent placement $(18,19)$.

In a series of 13 patients before the adoption of endovascular stents, Misthos et al. demonstrated that the tumor invaded the aortic adventitia only in $69 \%$ of cases (20). More importantly, only $8 \%$ of these patients had pathologic N0 disease, and the incidence of an unexpected N2 disease was as high as $31 \%$. This situation suggests that chemotherapy is still a major component of treatment for patients exhibiting aortic invasion. There are studies providing suggestions that confer a survival benefit in aortic resections in patients with NSCLC compared to that with subadventitial dissection, although such studies have been retrospective and included limited experience (21).

No study has yet analyzed the effects of preoperative chemotherapy or radiotherapy on outcomes and technical difficulties. Experience in this context is expected to increase in the future because aortic endografts would be available before neoadjuvant therapy to facilitate an aggressive surgical approach, including en bloc resection of the aorta if indicated. Induction chemotherapy, concurrent chemoradiation, or sequential chemoradiation therapy has been used prior to surgery to improve the chances of $\mathrm{R} 0$ resection and possibly for long-term survival $(4,22)$.

Aortic wall resection requires an $\mathrm{R} 0$ resection. This is the all-or-none rule. If there will be an aortic wall resection, surgery should be complete and R0. These patients should also be carefully assessed preoperatively to rule out mediastinal lymph node involvement (N2 disease) and distant metastasis.

\section{Technical considerations}

Tumors invading the aorta by simply abutting the aortic adventitia could be treated by local resection of the adventitia (Figure 2). However, the problem is when do the tumors invade through all the layers of the aortic wall and extend into the media. The location of the aortic involvement is important to determine the steps of the surgery. The highest level of concern occurs when the aortic arch is involved.

Such tumors require specific level of knowledge about aortic surgery and expertise. The involvement of the supra-aortic vessels, such as the subclavian artery, the vertebral artery, and the carotid artery, may require specific preoperative workup and planning during surgery.

For example, evaluation of the circle of Willis by MRI may be required to assure a resection of one of the vertebral arteries with the subclavian vessels. In case a hypoplasia of the contralateral vertebral artery exists or in the absence of adequate posterior communicating arteries, reconstruction of the vertebral artery may be required to prevent a stroke $(23,24)$.

Resection of lung cancer invading the aortic arch may require exceptional surgical techniques under $\mathrm{CPB}$ use, such as deep hypothermia, antegrade and retrograde cerebral perfusion, to achieve a complete resection by protecting the brain (25-27). Recently, several authors have used thoracic endografts to provide a safe aortic wall resection in patients with lung cancer. The major advantage of this method is that it avoids the use of CPB and achieves a safe and complete resection of these tumors (18). However, patients may require customized endovascular grafts, and an intraoperative decision-making may be cumbersome under these circumstances.

\section{Basic surgical techniques}

A large, left posterolateral thoracotomy provides the optimum exposure. Invasion to the vertebra, esophagus, and the primary PA should be carefully evaluated. Involvement of the descending aorta below the subclavian artery could be operated through resection and reconstruction of the descending aorta. The resection can be done either as an island or as a segmental resection of the aorta. In both resections, a clamp-sewn technique can be used, and there is a time restriction to take off the clamps and let the perfusion. Otherwise, the operation may end up in spinal cord ischemia.

The repair could be done with patch plasty (Figure 1) (28). Tube graft interposition may be preferred when the invasion involves a longer part of the aorta (Figures 3-5). The author 

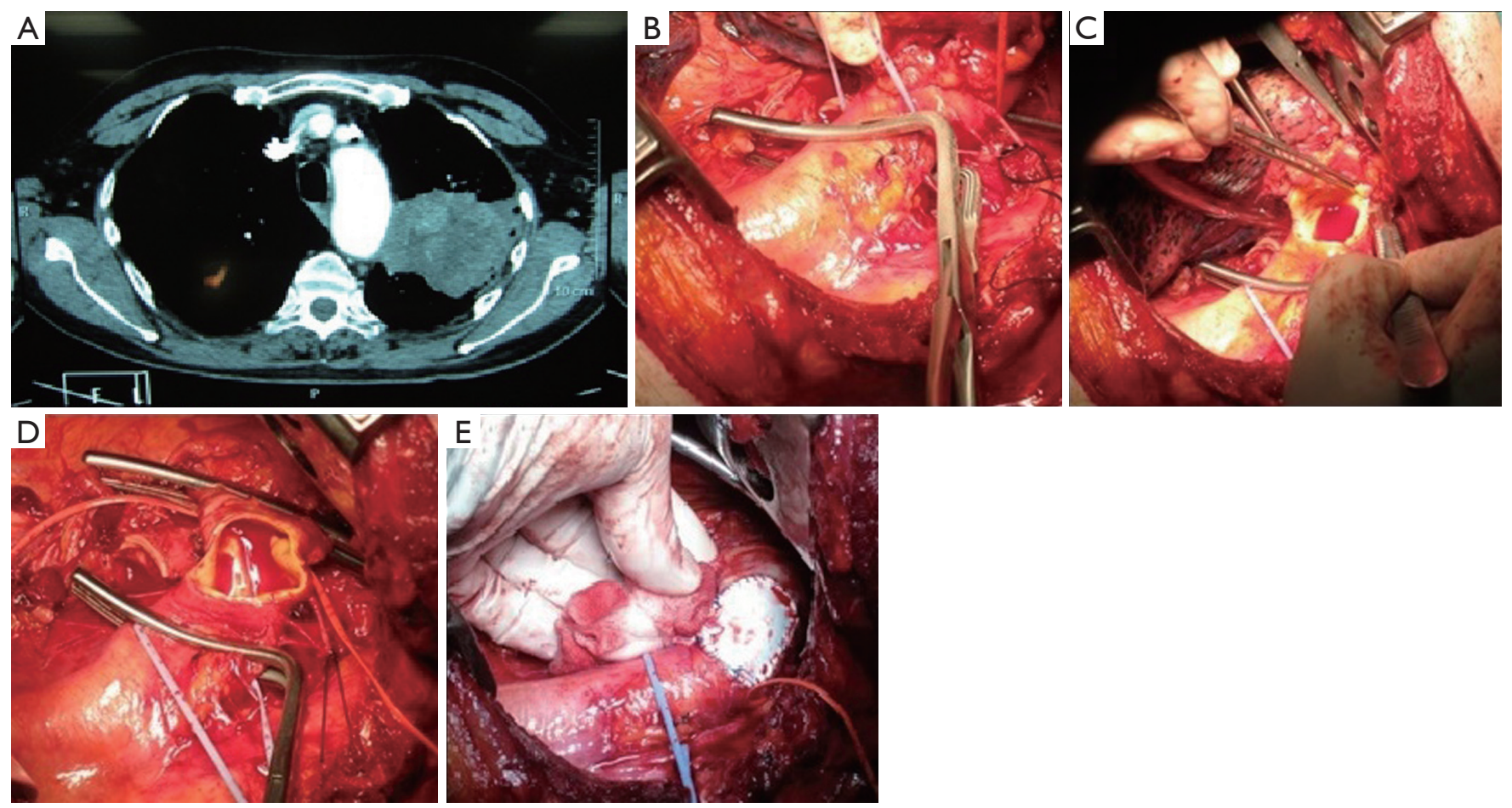

Figure 4 (A) Chest tomography of a patient with aorta invasion after induction chemotreatment; (B) clamping of aorta; (C) resection of Aorta that invaded by tumor; (D) image of resected aorta; (E) image after patch plasty of aorta.

of this chapter finds the patch plasty technique to be simple and preferable.

However, this clamp-sewn approach is associated with some risks such as systemic hypertension, stroke, and pulmonary edema of the contralateral lung, particularly when a pneumonectomy is performed. In most of our patients, except 2 of 11 , we performed a pneumonectomy operation.

There are several other options to prevent such risks. These options primarily include cardiac support techniques such as (I) venoarterial (VA) ECMO performed between the right atrium and the descending aorta, (II) left heart bypass without oxygenation of the blood performed from the left atrium to the descending aorta, and (III) the Gott shunt that passively connects the ascending aorta to the descending aorta. The aim of all these options is the preservation of the spinal cord and the abdominal organs from ischemia or hypoperfusion.

In bypass or VA ECMO techniques, a bypass is used to maintain about $50 \%$ of the cardiac output, and the upper part of the body is maintained with the flow coming from the heart. The lower part of the body is perfused by the bypass or the ECMO support.
One important aspect of the surgery is the blood in the pleural cavity, which might contain tumor cells. Although there might be no existing evidence, it is recommended that the blood aspirated from the surgical field should not be transfused back into the patient to prevent dissemination.

\section{Outcomes and conclusions}

A lung cancer with infiltration of the aorta generally has a poor outcome, and surgical resection has been known to be contraindicated for several years (29). Several studies have demonstrated that long-term survival might be possible after resection of the aortic adventitia (30-32). However, these patients were not those described in the discussion section of this article. In this article, we discuss about the patients who underwent resection of the involved aortic wall and required a graft replacement. Several articles have reported about patients who survived for about 3 years. All these articles recommend complete resection of the entire tumor with the aortic wall (33-36).

Preoperative induction therapy is strongly recommended for achieving a complete lung cancer surgery and has been used for treating $\mathrm{T} 4$ disease. 

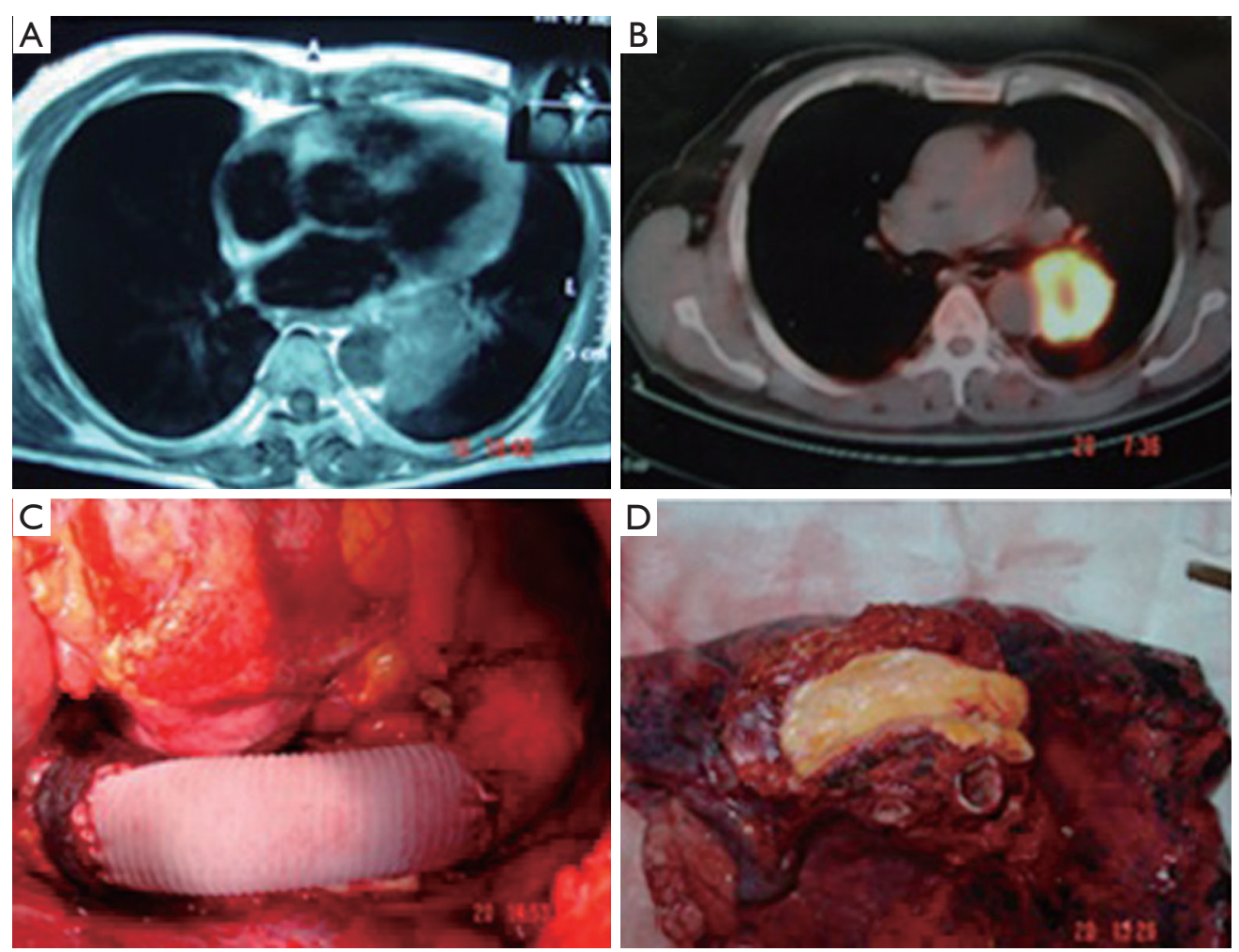

Figure 5 (A,B) Magnetic resonance imaging (A) and positron emission CT images of a tumor invaded aorta; (C) tube graft interposition to descending aorta. It was performed under Cardiopulmonary bypass; (D) resected parenchyma with the tumor invaded aorta.

In all the above mentioned studies, mediastinal lymph node status after induction treatment has been the major prognostic determinant of survival. Favorable outcomes for patients with postoperative pathologic N0 disease could be expected, but the outcome is still poor in $\mathrm{N} 2$ or $\mathrm{N} 3$ disease. Accurate diagnosis of mediastinal lymph node involvement is a must before planning for a surgical treatment. If there is no histologic evidence of mediastinal nodal metastasis after a series of investigations, including EBUS, EUS, mediastinoscopy, mediastinotomy, and VATS, a radical resection of the aorta could be performed by experienced centers and teams.

In conclusion, the rates of surgical morbidity and mortality are still high in patients who have undergone resection and reconstruction of the aorta, especially if an unplanned surgery is required. Preoperative induction therapy may be used safely. Appropriate use of cardiovascular techniques is the major determinant of highquality reconstructions. Encouraging long-term results might be found in patients with N0 disease.

\section{Acknowledgments}

Funding: None.

\section{Footnote}

Provenance and Peer Review: This article was commissioned by the editorial office, Shanghai Chest for the series "Extended resections for lung cancer". The article has undergone external peer review.

Conflicts of Interest: All authors have completed the ICMJE uniform disclosure form (available at http://dx.doi. org/10.21037/shc.2018.11.01). The series "Extended resections for lung cancer" was commissioned by the editorial office without any funding or sponsorship. AT served as the unpaid Guest Editor of the series and serves as an unpaid editorial board member of Shanghai Chest from Aug 2017 to Jul 2019. The authors have no other conflicts of interest to declare. 
Ethical Statement: The authors are accountable for all aspects of the work in ensuring that questions related to the accuracy or integrity of any part of the work are appropriately investigated and resolved.

Open Access Statement: This is an Open Access article distributed in accordance with the Creative Commons Attribution-NonCommercial-NoDerivs 4.0 International License (CC BY-NC-ND 4.0), which permits the noncommercial replication and distribution of the article with the strict proviso that no changes or edits are made and the original work is properly cited (including links to both the formal publication through the relevant DOI and the license). See: https://creativecommons.org/licenses/by-nc-nd/4.0/.

\section{References}

1. Farjah F, Wood DE, Varghese TK Jr, et al. Trends in the operative management and outcomes of T4 lung cancer. Ann Thorac Surg 2008;86:368-74.

2. Watanabe S, Asamura H, Miyaoka E, et al. Results of T4 surgical cases in the Japanese Lung Cancer Registry Study: should mediastinal fat tissue invasion really be included in the T4 category? J Thorac Oncol 2013;8:759-65.

3. Yildizeli B, Dartevelle PG, Fadel E, et al. Results of primary surgery with $\mathrm{T} 4$ non-small cell lung cancer during a 25 -year period in a single center: the benefit is worth the risk. Ann Thorac Surg 2008;86:1065-75.

4. Collaud S, Fadel E, Schirren J, et al. En Bloc Resection of Pulmonary Sulcus Non-small Cell Lung Cancer Invading the Spine: A Systematic Literature Review and Pooled Data Analysis. Ann Surg 2015;262:184-8.

5. Maurizi G, D'Andrilli A, Venuta F, et al. Bronchial and arterial sleeve resection for centrally-located lung cancers. J Thorac Dis 2016;8:S872-81.

6. Arakawa H, Kohno T, Hiki T, et al. CT pulmonary angiography and $\mathrm{CT}$ venography: factors associated with vessel enhancement. AJR Am J Roentgenol 2007;189:156-61.

7. Herman SJ, Winton TL, Weisbrod GL, et al. Mediastinal invasion by bronchogenic carcinoma: CT signs. Radiology 1994;190:841-6.

8. Munden RF, Swisher SS, Stevens CW, et al. Imaging of the patient with non-small cell lung cancer. Radiology 2005;237:803-18.

9. Gdeedo A, Van Schil P, Corthouts B, et al. Comparison of imaging TNM [(i)TNM] and pathological TNM [pTNM] in staging of bronchogenic carcinoma. Eur J Cardiothorac
Surg 1997;12:224-7.

10. Spaggiari L, Tessitore A, Casiraghi M, et al. Survival after extended resection for mediastinal advanced lung cancer: lessons learned on 167 consecutive cases. Ann Thorac Surg 2013;95:1717-25.

11. Postmus PE, Kerr KM, Oudkerk M, et al. Early and locally advanced non-small-cell lung cancer (NSCLC): ESMO Clinical Practice Guidelines for diagnosis, treatment and follow-up. Ann Oncol 2017;28:iv1-iv21.

12. De Leyn P, Vansteenkiste J, Lievens Y, et al. Survival after trimodality treatment for superior sulcus and central $\mathrm{T} 4$ non-small cell lung cancer. J Thorac Oncol 2009;4:62-8.

13. Langer NB, Mercier O, Fabre D, et al. Outcomes After Resection of T4 Non-Small Cell Lung Cancer Using cardiopulmonary Bypass. Ann Thorac Surg 2016;102:902-10.

14. Muralidaran A, Detterbeck FC, Boffa DJ, et al. Long-term survival after lung resection for non-small cell lung cancer with circulatory bypass: a systematic review. J Thorac Cardiovasc Surg 2011;142:1137-42.

15. Kauffmann M, Kruger T, Aebert H. Surgery on extracorporeal circulation in early and advanced non-small cell lung cancer. Thorac Cardiovasc Surg 2013;61:103-8.

16. de Biasi AR, Nasar A, Lee PC, et al. National Analysis of Short-Term Outcomes After Pulmonary Resections on Cardiopulmonary Bypass. Ann Thorac Surg 2015;100:2064-71.

17. Picone AL, Yendamuri S. Use of cardiopulmonary bypass in lung cancer surgery: focus on extended pulmonary resections for T4 non-small cell lung cancer. J Xiangya Med 2018;3:24.

18. Collaud S, Waddell TK, Yasufuku K, et al. Thoracic aortic endografting facilitates the resection of tumors infiltrating the aorta. J Thorac Cardiovasc Surg 2014;147:1178-82.

19. Marulli G, Rendina EA, Klepetko W, et al. Surgery for T4 lung cancer invading the thoracic aorta: Do we push the limits? J Surg Oncol 2017;116:1141-9.

20. Misthos P, Papagiannakis G, Kokotsakis J, et al. Surgical management of lung cancer invading the aorta or the superior vena cava. Lung Cancer 2007;56:223-7.

21. Wex P, Graeter T, Zaraca F, et al. Surgical resection and survival of patients with unsuspected single node positive lung cancer (NSCLC) invading the descending aorta. Thorac Surg Sci 2009;6:Doc02.

22. Perentes J, Bopp S, Krueger T, et al. Impact of lung function changes after induction radiochemotherapy on resected T4 non-small cell lung cancer outcome. Ann Thorac Surg 2012;94:1815-22. 
23. Watanabe T, Okada Y, Sakurada A, et al. Resection of apical lung carcinoma involving the vertebral artery. Ann Thorac Surg 2010;90:302-3.

24. Sekine Y, Saitoh Y, Yoshino M, et al. Evaluating vertebral artery dominancy before T4 lung cancer surgery requiring subclavian artery reconstruction. Surg Today 2018;48:158-66.

25. de Perrot M, Fadel E, Mussot S, et al. Resection of locally advanced (T4) non-small cell lung cancer with cardiopulmonary bypass. Ann Thorac Surg 2005;79:1691-6.

26. Hasegawa $S$, Bando $T$, Isowa $N$, et al. The use of cardiopulmonary bypass during extended resection of nonsmall cell lung cancer. Interact Cardiovasc Thorac Surg 2003;2:676-9.

27. Horita K, Higuchi S, Nakayama Y, et al. An updated report of a case of lung cancer resected using cardiopulmonary bypass. Thorac Cardiovasc Surg 1997;45:100-1.

28. Toker A, Tanju S, Ozluk Y, et al. Partial resection of the aorta and patch plasty with a simple clamping technique in a lung cancer patient. Interact Cardiovasc Thorac Surg 2011;12:827-8.

29. Lung and pleural tumours. Sobin LH, Wittekind CH.

doi: 10.21037/shc.2018.11.01

Cite this article as: Cosgun T, Kaba E, Ayalp K, Toker A. The decision making and techniques in lung cancer patients with aortic resection and reconstruction: surgery for lung cancer with aortic wall invasion. Shanghai Chest 2018;2:87. editors. UICC: TNM classification of malignant tumours (5th ed.). New York: John Wiley \& Sons, 1997:91-100.

30. Bernard A, Bouchot O, Hagry O, et al. Risk analysis and long-term survival in patients undergoing resection of T4 lung cancer. Eur J Cardiothorac Surg 2001;20;344-9.

31. Fukuse T, Wada H, Hitomi S. Extended operation for non-small cell lung cancer invading great vessels and left atrium. Eur J Cardiothorac Surg 1997;11:664-9.

32. Burt ME, Pomerantz AH, Bains MS. Results of surgical treatment of stage III lung cancer invading mediastinum. Surg Clin North Am 1987;67:987-1000.

33. Tsuchiya R, Asamura H, Kondo H. Extended resection of the left atrium, great vessels, or both for lung cancer. Ann Thorac Surg 1994;57:960-5.

34. Horita K, Itho T, Ueno T. Radical operation using cardiopulmonary bypass for lung cancer invading the aortic wall. Thorac Cardiovasc Surg 1993;41:130-2.

35. Okubo K, Yagi H, Yokomise H. Extensive resection with selective cerebral perfusion for a lung cancer invading the aortic arch. Eur J Cardiothorac Surg 1996;10:389-91.

36. Klepetko W, Wisser W, Birsan T et al. T4 lung tumors with infiltration of the thoracic aorta: is an operation reasonable? Ann Thorac Surg 1999;67:340-4. 